\title{
A TERCEIRIZAÇÃO NOS SERVIÇOS E SUAS CONSEQÜÊNCI AS NO CUIDAR EM ENFERMAGEM
}

\author{
[O utsourced services and their consequences to nursing care] \\ [ $L$ a tercerización en los servicios y sus consecuencias en el cuidar en enfermería]
}

Cláudia Zamberlan*
Hedi Crecência Heckler de Siqueira**

RESUMO: Neste artigo propõe-se refletir a respeito da influência da terceirização no processo de cuidar em enfermagem, enfocando dificul dades encontradas na mesma instituição das unidades não terceirizadas quanto ao cuidado de enfermagem e resolutividade de problemas em clientes submetidos a procedimentos hemodinâmicos que, após a intervenção são internados e/ou retornam às unidades comuns da Instituição que terceirizou os serviços hemodinâmicos. A experiência evidencia a necessidade de uma equipe integrada entre os dois serviços, podendo utilizar-se da educação continuada em serviço, como forma de resgatar conhecimentos considerados fundamentais para 0 cuidado integral dos clientes, bem como, uma profissão mais comprometida com o ser e o fazer enfermagem.

PALAVRAS-CHAVE: Terceirização; Cuidados de enfermagem; Educação continuada.

\section{INTRODUÇÃO}

As transformações tecnológicas na Á rea da Saúde vêm provocando modificações no processo de cuidar, visto que têm exigido, constantemente, a qual ificação dos profissionais com o propósito de prestar um cuidado mais eficiente, ou seja, o mesmo que eficaz, que produz o efeito desejado ${ }^{(1)}$.

0 cotidiano do trabalho de enfermagem está permeado pelas interrelações com os demais profissionais que atuam em âmbito hospital ar. N este sentido, as pessoas do sistema organizacional de cuidados de enfermagem utilizam um espaço geográfico e simbólico de um convívio humano muito próprio e, a princípio, de uma objetividade muito clara. Isto demonstra a importância singular da

\footnotetext{
*Enfermeira Docente do Curso Técnico em Enfermagem da Escola Nossa Senhora de Fátima. Santa M aria, RS. M estranda em Enfermagem pela Fundação Universidade do Rio Grande (FURG).

**Enfermeira D ocente do Curso de Pós-Graduação em Enfermagem da Fundação Universidade do Rio Grande (FURG). D outora em Filosofia da Enfermagem pela Universidade Federal de Santa Catarina (UFSC).
}

interação entre as equipes no ambiente organizacional hospitalar, na busca da qualidade da assistência (2).

A reorganização no mundo do trabal ho caracteriza um conjunto de modificações. D entre estas, pode-se citar a forte influência da terceirização nos Serviços de Saúde. Hoje, as instituições hospitalares possuem diversas áreas terceirizadas, como serviços de diagnósticos por imagem, laboratórios, bancos de sangue, nutrição, lavanderias, higienização, dentre outros que, se agregados, totalizam grande parte das forças de trabal ho em inúmeras instituições públicas e privadas. A utilização da força de trabalho é o próprio trabalho. 0 comprador da força de trabalho consome-a fazendo o vendedor dela trabal har ${ }^{(3)}$.

Cada serviço compreende um grande número de profissionais, indivíduos com características, val ores, sentimentos e saberes específicos que, na sua heterogeneidade, são capazes de contribuir para relações integradoras, enriquecendo 0 todo com suas particularidades. Em uma organização hospitalar estruturada em serviços, cada um destes constitui um subsistema dentro de um sistema maior ${ }^{(4)}$.

Esta idéia busca explicitar como deveria ocorrer a interrelação dos serviços hospitalares, porém as relações integrativas, no que tange ao conhecimento técnico e prático, na área da enfermagem, muitas vezes escapam da visão acima descrita. Partindo, pois, deste enfoque, surgiu a proposta de refletir sobre a influência da terceirização no processo de cuidar em enfermagem, procurando visualizar, especificamente, uma unidade diagnóstica e terapêutica por imagem de al ta complexidade - hemodinâmica - visto que, a partir da prática profissional vivenciada, foi constatada a fal ta de preparo e de conexão entre as equipes de enfermagem, ao cuidarem de clientes submetidos a intervenções hemodinâmicas. Cabe ressaltar que o serviço de hemodinâmica, terceirizado na instituição em referência, realiza a terapêutica e o diagnóstico cardiovascular, recupera esta clientela nas primeiras horas pós-intervenção, encaminhando-a, posteriormente, para as unidades de internação não terceirizadas.

Diante disto, fez-se presente a necessidade de reflexão sobre o tema, visto que, independentemente da área de 
atuação, 0 trabal ho de enfermagem deveria estar interligado, constantemente, com as diversas áreas de inserção institucional, priorizando, assim, o cuidado singular à clientela.

Objetiva-se, a partir desta vivência analisar e refletir a influência da terceirização nos serviços de saúde e sua conseqüência no processo de cuidado de enfermagem.

\section{RELATANDO A EXPERIÊNCIA}

Este artigo possui como base a experiência profissional vivida e que se traduziu em diversos questionamentos acerca dos cuidados prestados pela enfermagem, como, por exemplo, por que os profissionais de enfermagem, que atuavam nas unidades de internação, não possuíam e/ou demonstravam conhecimentos acerca do cuidar de pacientes submetidos a procedimentos hemodinâmicos? Como realizar uma proposta de educação continuada para que os mesmos obtivessem estes conhecimentos? Neste sentido, 0 estudo aborda as equipes de enfermagem de uma unidade de cardiologia invasiva terceirizada e demais unidades de internação de um hospital privado situado na região central do Rio Grande do Sul.

0 problema exposto refere-se a minha vivência profissional, como enfermeira assistencial, em uma unidade de hemodinâmica, na qual senti a dificuldade, por parte dos outros profissionais das unidades de internação, de prestarem um cuidado singular para a clientel a que era submetida à cateterização cardíaca diagnóstica e intervencionista. Dificuldades estas que englobavam, principalmente, 0 não reconhecimento de complicações na região cateterizada, assim como os cuidados específicos após a cateterização cardíaca. A pós a recuperação imediata na unidade de hemodinâmica a clientela era encaminhada para as unidades de internação, para a recuperação.

A I guns clientes que apresentavam certas complicações tardias, traduzidas em sangramento inguinal, reflexo vaso-vagal, Iombal gias, hematomas na região cateterizada, não eram avaliados corretamente pelos profissionais das unidades, talvez por um desconhecimento dos procedimentos real izados, e isto se traduzia no desl ocamento dos profissionais da hemodinâmica até as unidades de internação para a avaliação destes clientes, o que, na maioria das vezes, não eram complicações severas, mas reações esperadas em decorrência do tratamento instituído.

Essa atitude profissional de não conhecimento acerca das referidas complicações, muitas vezes, acarretava um descrédi to por parte dos clientes, pois não se sentiam verdadeiramente "cuidados", ocasionando problemas e inquietude, na medida em que a enfermagem deveria estar fundamentalmente integrada visando um único objetivo o cuidado humanizado e integral aos pacientes.

A credita-se, contudo, que a tecnologia e as novas áreas de atuação na enfermagem trouxeram dúvidas aos profissionais e que os serviços terceirizados e os não tercei rizados criaram, entre si, uma barreira em relação ao cuidar, barrei ra esta que não deveria existir quando se trata em cuidar do outro. Hoje, algumas providências já estão sendo implementadas para que o profissional se torne conhecedor destes novos procedimentos, habilidades, pois há maiores possibilidades de atualização na área. 0 que se faz necessário é que os profissionais das unidades de internação busquem estes conhecimentos e que oportunizem aos profissionais do setor terceirizado a troca de saberes, pois o trabalho, quando é realizado como um todo integrado, é mais eficiente, valorizado e conduz à realização pessoal e profissional.

\section{CONHECENDO O PROCESSO DE TERCEIRIZAÇÃO NO AMBIENTE HOSPITALAR}

A terceirização é entendida como interveniente, intermediário na abordagem administrativa, caracterizandose como uma modalidade através da qual se coloca um serviço de terceiros em uma instituição que assumirá o desempenho desse serviço eque pode, desta maneira, ser chamada de atividade tercei rizada ${ }^{(5)}$.

A I guns estudiosos nesta área definem este processo como sendo a busca pela qual a instituição visa alcançar maior e melhor qualidade e produtividade, redução de custos e, desta forma, a atividade deixa de ser real izada pelos funcionários de uma empresaA (instituição hospital ar) para ser transferida aos funcionários de uma empresa $B$ (serviço terceirizado), ocorrendo assim um processo de transferência de funções e/ou atividades, podendo incluir tanto as etapas do processo produtivo, ou atividades fins, da chamada "empresa origem", como atividades ou serviços de apoio, também denominados de meios; nestes casos pode-se citar como exemplos: os serviços das lavanderias, de limpeza, manutenção, nutrição, dentre outros.

Pelo exposto, pode-se entender que o processo de terceirização deveria ser inseparável do processo de parceria, ainda que sua finalidade seja, sobretudo, otimizar o trabalho e, como conseqüência, obter maior produtividade, qualidade e diminuição de custos.

A terceirização no setor hospitalar se deve, sobretudo, ao aumento nos custos com a saúde e nesta área este processo deveria desenvolver a parceria, sobrepondo o coletivo ao individual.

0 trabal hador da saúde se coloca em um terreno plurinstitucional ${ }^{(6)}$, isto nos remete a pensar que este "terreno" engloba não somente o homem, mas também a natureza e todo o seu processo, como, ainda, a força de trabaIho que põe a vida em movimento.

A onda de qualidade, terceirização e automação ou qualquer outra forma de diminuir a necessidade de pessoal parecem idéias que ainda não atingiram os serviços de enfermagem hospital ar, porém a forte idéia de que a presença do cuidador junto ao cliente/paciente é muito importante e não se esgota ${ }^{(2)}$. Essa afirmativa nos leva a refletir a respei- 
to das inúmeras e rápidas transformações que se fazem presentes no trabalho da enfermagem. Pode-se constatar que, em relação à força de trabal ho da enfermagem, a idéia de tercei rização já atingiu diversas instituições. Essa nova realidade necessita de adaptações em busca de novas formas de convivência, do desenvolvimento de conhecimento específico e da interconexão/integração dos serviços ${ }^{(4)}$.

A enfermagem encontra-se envolvida neste processo, uma vez que participa da equipe multiprofissional, prestando cuidado, planejando e coordenando ações e possibilitando espaço com vistas à prevenção, promoção e recuperação da saúde.

Como já citado, anteriormente, dentre as unidades que mais se destacam como terceirizadas encontram-se as de diagnósticos e intervenção por imagem, motivo escolhido como objeto de reflexão, e por isso ressaltar-se-á aspectos referentes, especificamente, à unidade de hemodinâmica.

A unidade de hemodinâmica é um setor que estuda o estado normal e patológico do sistema cardiovascular, intervindo quando necessário através de procedimentos altamente complexos. $\mathrm{N}$ ão encontramos na literatura uma definição ampla acerca de procedimentos de alta complexidade, porém há um consenso de que os mesmos sejam aqueles procedimentos que apresentam custos elevados, equipamentos de ponta e condutas altamente complexas e especializadas e que, na maioria das vezes, ainda não foram adotados como rotina nos tratamentos.

Este é o caso dos procedimentos realizados nas unidades de hemodinâmica, onde podemos destacar cateterismos cardíacos, angioplastias coronarianas, implantes de stents coronários, armações metálicas usadas para manter abertos os vasos do organismo que não funcionam de forma correta, implantes de balão intra-aórtico, dentre outros, e que, por ainda não serem rotineiros em muitos ambientes hospitalares, tornam-se um entrave ao cuidado dos profissionais da enfermagem que atuam nas unidades de internação, pois, não ocorre um conhecimento específico por parte destes acerca da técnica, das complicações e da especificidade do cuidado de enfermagem a ser prestado.

Faz-se, desta maneira, importante analisar o que é cuidado de enfermagem e como deveria acontecer a integração dos serviços terceirizados com os não tercei rizados real izados na mesma instituição, porém, com equipes de enfermagem distintas, objetivando a produção de um trabal ho interconectado com efeitos mais positivos ao cliente submetido a procedimentos hemodinâmicos.

\section{A INTERRELAÇÃO DO CUIDADO NAS UNIDA- DESTERCEIRIZADAS COM AS DEMAIS EM ÂM- BITO HOSPITALAR QUE TERCEIRIZA O SERVI- ÇO}

A o visualizar o processo de terceirização faz-se urgente o repensar acerca do cuidado que estamos prestando à clientela em estudo e desta forma compreender a dificuldade de integração entre as diferentes áreas de atuação.

A pesar de existirem hoje tecnologias extremamente abrangentes, vêem-se ainda inúmeras necessidades sentidas pelos cuidadores no que diz respeito aos procedimentos de ponta realizados nos serviços terceirizados. Ocorre que 0 cuidador das unidades não terceirizadas, por não possuir conhecimentos, habilidades profissionais relativas às intervenções de alta complexidade, necessárias para satisfazer suas dúvidas, não pode traçar melhores estratégias de cuidado e, conseqüentemente, o cliente externo é que sofrerá os prejuízos. Para amenizar a descontinuidade, seria necessário proceder-se à interrelação de conhecimentos entre os profissionais de enfermagem dos setores terceirizados e não terceirizados, oportunizando ao profissional cuidador uma produção cooperativa de cuidado e o exercício de uma atividade humanizada para a clientela.

Falar em cuidado, no âmbito da saúde, é culminar com a idéia de que o cuidado conduz à promoção da saúde e à cura e o modo como se operam os serviços de saúde defini-se como a produção de cuidado ${ }^{(7)}$. Desta maneira produzimos cuidado na medida em que conhecemos os sujeitos aos quais prestamos o cuidado. Surge, desta forma, a necessidade de vínculo entre os profissionais dos setores terceirizados e os não terceirizados, com o propósito de troca de experiências, objetivando, ao final, o melhor atendimento possível ao cliente.

O que se observa, na prática, é a falta de uma educação continuada intersetorial facilitando o processo de aprendizagem e proporcionando um cuidado mais eficaz.

\section{EDUCAÇÃO CONTINUADA: UMA NECESSIDADE}

A educação continuada, nos serviços de enfermagem, torna-se de fundamental importância, visto que possibilita ao trabalhador um aprimoramento e uma qualificação em relação a novos implementos técnicos e científicos, além do que, proporciona um resgate científico nas organizações. Para a experiência acima relatada, acredita-se que a educação continuada seja a base sólida para evitar e/ou tentar solucionar de forma rápida as eventuais complicações que podem advir em decorrência do procedimento hemodinâmico.

No que diz respeito à evolução tecnológica e ao processo de conhecimento

um novo trabalho em contínua construção e reconstrução, com base na motivação e auto-estima, deve ser criativamente despertado, no sentido de desenvolver caminhos contra a entropia e, conseqüentemente, acompanhar o constante avanço tecnológico que está a produzir novos produtos/serviços que irão modificar o mercado emergente. A s organizações precisam capacitar-se para acompanhar esta evolução traçando estratégias que irão orientar o caminho a ser seguido. É necessário investir nos trabalhadores, clientes/internos, maior bem da organização, oportunizando uma aprendizagem contínua, para que possam satisfazer as suas necessidades pesso- 
ais e profissionais e participar da análise das ameaças e oportunidades que se apresentam, traçando as melhores estratégias para encontrar as soluções que venham ao encontro das necessidades dos clientes ${ }^{(4: 57)}$.

Para isso, torna-se necessário que o trabalhador esteja engajado em um processo de mudança, absorvendo assim ao máximo o que a educação possa proporcionar e, por fim, analisar quais estratégias são adequadas para a resolução dos problemas vivenciados no cotidiano.

0 suj eito que se abre ao mundo e aos outros inaugura, com um gesto, a relação dialógica em que se confirma como inqui etação e curiosi dade, como inconcl usão em permanente movimento na história ${ }^{(8)}$.

Esta relação dialógica, que o autor expressa acima, é que constrói e reconstrói o saber, independente da existência de duas instituições, pois será a partir da reflexão crítica das mesmas e do estabel ecimento de ajustes e relações de trocas de saberes que se dará um "movimento permanente na história", movimento este que contempla o conhecimento e o saber contínuo.

A educação continuada éo ponto principal para aquisição do conhecimento/saber que pode propiciar o sucesso de qual quer atividade al iada à parti ci pação ativa e comprometida das instituições/organizações em que os indi víduos estão inseridos. A educação permanente associada a uma educação continuada, planejada pela instituição, de forma sistemática, faz com que o trabal hador conquiste seu espaço, sua real ização e reconhecimento pessoal e profissional, garantindo assim seus direitos de cidadão ${ }^{(9)}$.

Os autores supracitados abordam um ponto fundamental dentro da educação, onde enfatizam que precisamos estar abertos ao mundo, às novas formas de aprender, aos conhecimentos tecnológicos, isto tudo servindo como inquietação em nosso ser. Pensamos que, desta maneira, a enfermagem poderá prestar um cuidado mais humano e eficiente, pois é na busca da mudança e na construção contínua do conhecimento que se faz do cuidador um ser integrado nas instituições, oportunizando-Ihe sentir-se satisfeito, realizado e feliz.

Reportando aos serviços terceirizados e não terceirizados, situados em uma mesma instituição hospitalar, a educação continuada seria um caminho oportuno e eficaz, servindo como uma estratégia instrumental para que as dificuldades, sentidas no cuidar a clientela, consigam ser superadas. A ssim, a qualidade da profissão está no caminho de sua permanente renovação e não apenas banalizada em resultados repetidos, pois os eventos social izantes do conhecimento recuperam a competência de modo sistemático ${ }^{(10)}$.

Este pensamento, se real mente colocado em prática nas instituições, através da educação continuada, impede 0 isolamento profissional, proporcionando compartilhar os saberes, o que representaria o desempenho de habilidades e competências únicas com vistas a um atendimento integral.
0 estabel ecimento de uma educação continuada em relação a estes serviços poderia ocorrer de maneira sistemática, periódica, através de reuniões de estudo com as equipes envolvidas, de workshops, cursos, palestras, trabaIhando, em um primeiro momento, as dificuldades e, posteriormente, as melhores estratégias de resolução das mesmas, configurando assim, as possibilidades de socializar 0 conhecimento, traduzindo-o num melhor cuidado.

Entretanto, para concretizar este agir, é necessário que as instituições não visualizem somente as suas ações, mas que tracem, conjuntamente, protocolos nos quais seja definida e assegurada a continuidade ef etiva e eficiente do cuidado, através de equi pes de enfermagem habilitadas. Esta etapa além de val orizar o cliente oportuniza o crescimento pessoal e profissional das equipes assegurando-Ihes maior significação através dos resultados obtidos pelo seu trabaIho.

\section{CONSIDERAÇÕES FINAIS}

A s organizações, atual mente, buscam cada vez mais a terceirização como processo de facilitação de atendimento e diminuição de custos. Porém, o que se observa é a falta de interação intersetorial o que, por vezes, leva à demora nas informações e resolução dos problemas apresentados.

$\mathrm{N}$ ão se pode admitir, hoje, que a profissão enfermagem se torne fragmentada diante da terceirização dos serviços, pois visamos 0 atendimento ao ser humano de maneira única e integral, priorizando, assim, a unicidade e individualidade de cada um. À medida que fragmentamos 0 cuidado de enfermagem, tornamo-nos inconsistentes e a clientela descrente e fragilizada em decorrência de nosso atendimento.

Precisa-se, pois, que a enfermagem, independente do trabal ho que realiza, esteja integrada com as demais áreas, na busca de aperfeiçoamento contínuo, porque este se traduz no mel hor atendimento e na confiança que a clientela dispensa ao cuidador.

A credita-se, contudo, que a educação continuada, nas suas mais diversas formas, com a proposta de desenvolvimento do conhecimento através do auxílio de incubadoras ${ }^{(9)}$, apresenta-se como o caminho para que os setores de enfermagem dos serviços terceirizados e não tercei rizados busquem eficiência nas relações de trabal ho, onde a socialização dos saberes possa se traduzir na reconstrução de um cuidado mais integrado, humanizado, produtivo e eficiente.

ABSTRACT: This experience report intends to contemplate and to analyze the influence of outsourced services in the process of nursing care, focusing on the difficulties found in the other units of the same institution without contracted services in relation to nursing care and problem-solving rendered to clients submitted to hemodynamic procedures by outsourced providers. Those clients are either admitted 
or return to the units after intervention. The experience evidences the need of an integrated team in both services, who could use ongoing education at work as a way to gather knowledge, fundamental to provide clients with integral care, as well as a more committed professional to the nursing way of being and doing.

KEY WORDS: Engaged services; Nursing care; Continuous education.

RESUMEN: Este informe de experiencia tiene el objetivo de ponderar y analizar la influencia de los servicios agregados en el proceso de cuidar de los enfermos en las enfermerías, mientras enfoca dificultades encontradas en unidades de la misma institución, con y sin servicios agregados, en la resolución de los problemas con clientes sometidos a los procedimientos de hemodinámica, los cuáles se internan después de la intervención y/o regresan a las unidades comunes en la institución con servicios de hemodinámica agregados. La experiencia evidencia la necesidad de un equipo integrado en ambos servicios, cuando podría usarse la educación continua al servicio como la forma de lograr el conocimiento considerado fundamental para el cuidado íntegro de los clientes, así como tornar la profesión más comprometida con el ser y el hacer de los servicios de enfermería.

PALAVRAS CLAVE: Servicios agregados; A tención de enfermería; Educación continuada.

\section{REFERÊNCIAS}

1. Ferreira A B H. M ini A urélio o dicionário da língua portuguesa. 6. ed. Curitiba: Posigraf; 2004.

2. Eerdmann A L. Sistemas de cuidados em enfermagem. Pelotas: UFPEL, 1996. (Série de teses em enfermagem)

3. M arx K. 0 capital: crítica da economia política. Livro 1: 0 processo de produção do capital. Rio de Janeiro: Difel; 1968. 1 v.

4. Siqueira HCH. As interconexões dos serviços no trabalho hospitalar: um novo modo de pensar e agir. [tese]. Florianópolis: Universidade Federal de Santa Catarina; 2001.

5. Carvalcanti Jr O. A terceirização das relações laborais. São Paulo: L. Traduções; 1996.

6. Ramos FRS. Obra e manifesto: o desafio estético do trabalhador da saúde. Florianópolis: UFSC; 1996. (Série teses em enfermagem)

7. M erhy EE. O SUS e um dos seus dilemas: mudar a gestão e a lógica do processo de trabalho em saúde - um ensaio sobre a micropolítica do trabalho vivo. Rio de Janeiro: CEBES; 1996.

8. Freire P. Pedagogia da autonomia: saberes necessários à prática educativa. São Paulo: Paz e Terra; 1996.

9. Cecagno D. Serviço de educação continuada na enfermagem nas instituições de saúde do município de Rio Grande. [dissertação] Rio Gran- de: Fundação U niversidade do Rio Grande; 2003.

10. Demo P. Educar pela pesquisa. 6. ed. Campinas: A utores A ssociados; 2003.

ENDERÇO DOSAUTORES:

Rua Floriano Peixoto, 1899/204

Santa M aria-RS

97015-373

claudia_z@terra.com.br

Cogitare Enferm 2005 set/dez; 10(3):71-5 